\title{
Investigation on Voltage Quality Problems on the Process of Cement Industry Production in Indonesia: A Case Study of Cement Kupang Factory - Indonesia
}

\author{
Julius Sentosa Setiadji ${ }^{*}$, Daniel Rohi, and Yoanne Flantine Mozes \\ Electrical Engineering Department, Petra Christian University, Jl. Siwalakerto 121-131, Surabaya, Indonesia, 60236
}

\begin{abstract}
The decline in the quality of electric power becomes a serious problem in the industrial sector and affects a significant cost loss. One of the dominant power quality problems is the voltage dip. The use of electric motors in an industry becomes one of the main causes. This paper discusses the investigation on voltage dip problems at a cement factory at Kupang,, Indonesia. The cement factory uses an induction motor as the prime mover and is proven to trigger a voltage dip because of its high starting current. Based on the observed data of the disturbance, a single line diagram was created. The single line diagram was analyzed using an equivalent circuit. It was found out that as the induction motor was started, it created a very significant voltage drop as of $20.43 \%$ to $62.26 \%$. The voltage dip correlated to the capacity of the induction motor used. The larger the capacity of the induction motor, the larger the voltage dip occured.
\end{abstract}

Key words: Induction motor, power quality, voltage dip.

\section{Introduction}

The availability of qualified electrical energy is one of the important factors for the sustainability of the operation of an industrial estate. The quality of electrical energy is determined by two main factors: The availability of continuous energy or minimal power outages and electrical energy characteristic. The characteristics of the electrical energy volumes are guaranteed in accordance with the minimum requirements for the equipments to work securely and efficiently. The existence of continual electrical power distribution in and industrial area is of utmost important. The poor quality of the electric power, can stop the production process, especially in industries using sensitive loads such as control equipments. If this problem is not handled properly, a significant financial loss will be resulted.

The problems faced by a power system in the supply of electrical energy need to be investigated thoroughly and continuously. Then the main cause of the disturbance that occurs, will be obtained. One of the most common disruptions to power systems is the blurring of the voltage. This disturbance is a transient disturbance in the electric power system, ie a momentary voltage drop in the power system network. Cement Industry is one of the industries requiring considerable electric power from the power system network. In the production process of the cement industry, electric motors both large and small are used greatly.

The use of electric motors is causing the problem of decreasing quality of voltage in the electrical system of factories. The problem often arises is the voltage dip. Based on the observed disturbance data on a regular basis, the cause and effect of the voltage dip was identified. These data were used as parameters in the designated equivalent circuit. Then the data was analyzed to give recommendations as a corrective action. Voltage sags is one of the major problems in the industry and has provided significant financial losses [1,2].

\footnotetext{
${ }^{*}$ Corresponding author: julius@petra.ac.id
} 


\section{Voltage dip problems}

The definition of a voltage dip according to IEC (International Electrotechnical Commission) is a brief interruption of a sudden termination of voltage at all phases at a certain point in the power supply system below the threshold disturbance (usually $10 \%$ of nominal voltage) followed by restoration after a short time interval. In other words, a sudden voltage reduction at some point in the power supply system is below the dip limit (typically $90 \%$ of nominal voltage) followed by recovery after a short interval. The above definition is shown in Figure 1 [1]. Voltage is a phenomenon of decreasing the voltage amplitudes $(\Delta \mathrm{V})$ to its nominal price over the time interval t. This phenomenon is usually caused by a sudden disturbance or change in load $[3,4]$.

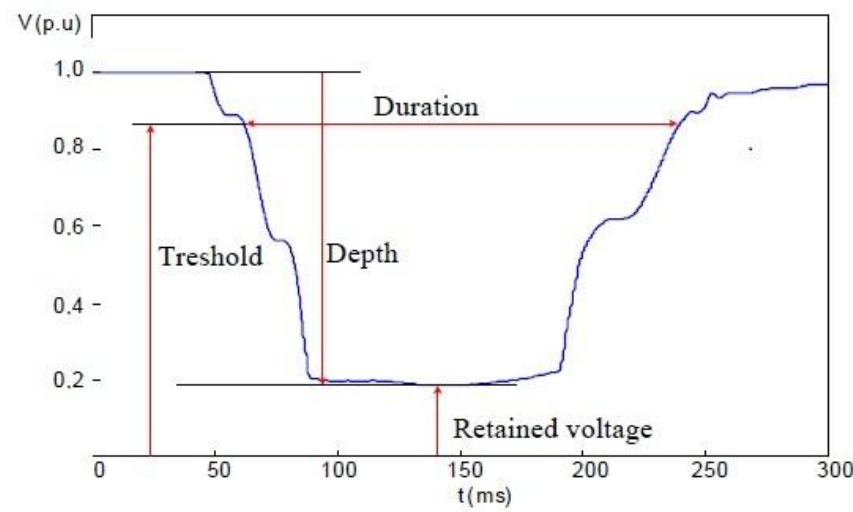

Fig. 1. The basic concept of a voltage dip [1].

When an induction motor is started directly at full voltage then the induction motor will draw a start current of 5 to 7 times the full load current. A high start current is required for the induction motor to obtain sufficient torque to start rotating. The presence of a large start current which is suddenly withdrawn from the power system can cause a voltage dip. The voltage dip induced by the induction motor start current depends on the motor capacity, the motor power factor, the system impedance and the starting method $[4,5,7]$.

Table 1. Sensitivity of equipment to voltage dip [4].

\begin{tabular}{|c|c|c|}
\hline Type of Equipment & $\begin{array}{c}\text { Remaining } \\
\text { Voltage } \\
\text { (\%) }\end{array}$ & $\begin{array}{c}\text { Time } \\
\text { Duration } \\
\text { Max } \\
\text { (ms) }\end{array}$ \\
\hline Motor starter & 50 & 40 \\
\hline Variable speed motor with electronics & 85 & 10 \\
\hline Programable Logic Control & 50 to 90 & 8 to 20 \\
\hline Frequency Inverter & 82 & 1.5 \\
\hline Variable speed drive rectifier & 50 to 80 & 2 to 3 \\
\hline Process controller & 70 & $<8$ \\
\hline Direct current drive controller & 88 & $<8$ \\
\hline Personal Computer & 50 to 70 & 60 to 160 \\
\hline
\end{tabular}

\section{Results and discussion}

Observations were conducted and the data were recorded periodically to the operation of three large induction motors. The characteristics of the three motors are as follows: The first condition is one piece of motor with the power of 1000 $\mathrm{kW}(120 \mathrm{~A})$. This motor is used as the Cement Mill Motor. The second condition is two pieces of motors with the power $460 \mathrm{~kW}$ (55 A). This motor is used as the Raw Mill Motor and Ventilator Motor. The motors in the Cement Factory operate non-stop during the production process. The configuration of the distribution chain and the extent of each piece of the equipment are shown in Figure 1. Based on the data in Figure 1, a series of substitute drawings were made for further analysis [8-10]. 


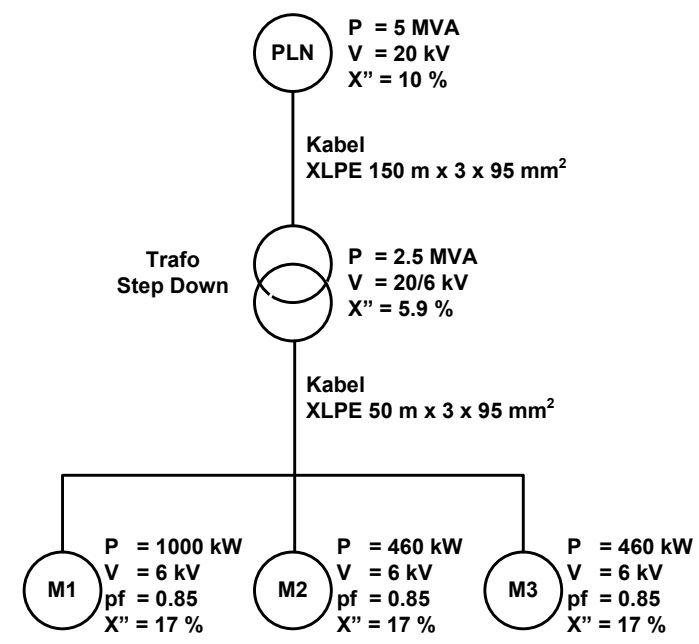

Fig. 2. Schematic of distribution circuit impedance.

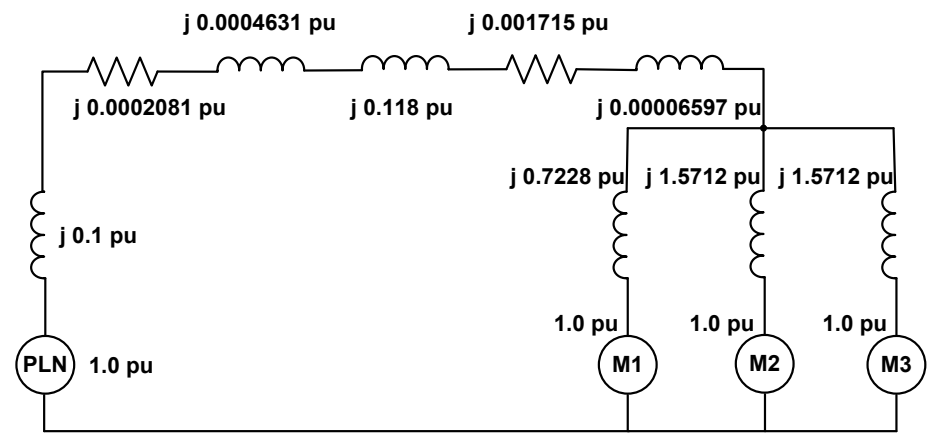

Fig. 3. Equivalent circuits of distribution networks.

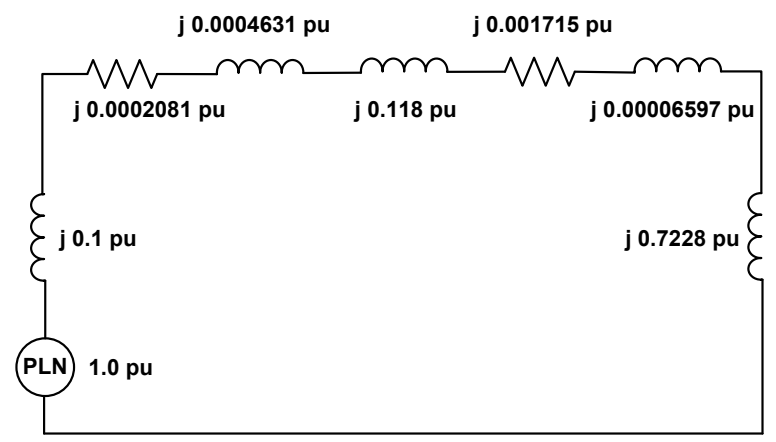

Fig. 4. The equivalent circuit at M1 start with the condition of M2 and M3 has not been activated.

Based on the sequence mentioned above, the voltage dip, occuring when the motor starts, can be calculated by the following Equation (1):

$$
\mathrm{V}=[\mathrm{Xpln}+\mathrm{Z} 1+\mathrm{Xtrafo}+\mathrm{Z} 2] \times[6 \times \mathrm{I} \text { pu1 }]
$$




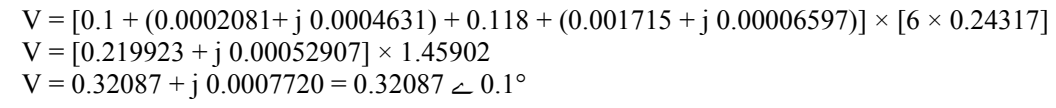

$\Delta V=\frac{0.32087}{1.0} \times 100 \%=32.8 \%$

The possibility of the operation of the three motors is presented in Table 2. Based on the data on the equivalent circuits, calculations and analysis were performed as described above. The calculation results are presented in Table 3.

Table 2. Possible operating conditions of motor and equivalent circuit.

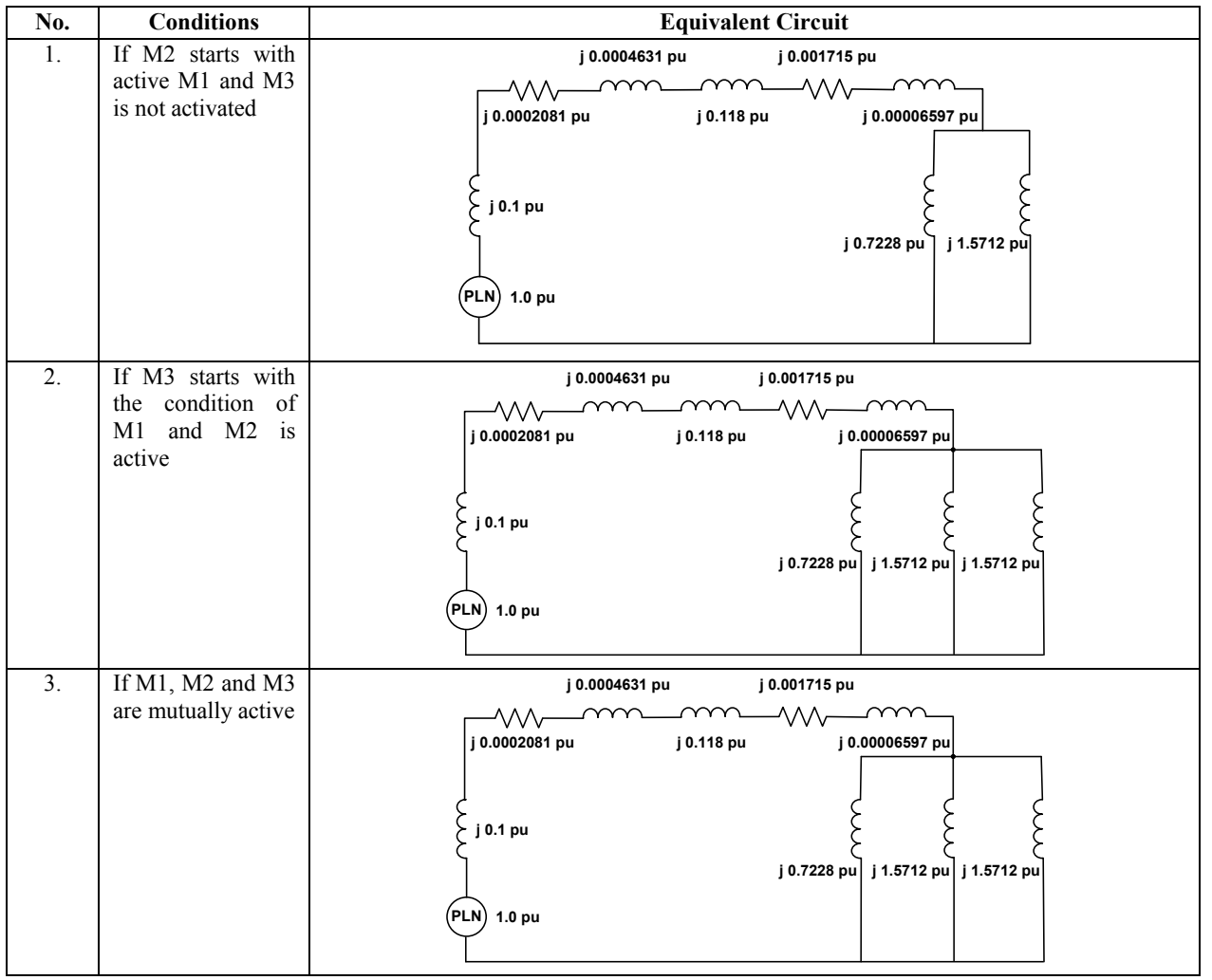

Table 3. Voltage dip that occurs when the motor starts

\begin{tabular}{|c|c|c|c|c|}
\hline \multirow[b]{2}{*}{ Condition } & \multirow[b]{2}{*}{$\begin{array}{c}\text { Dip } \\
\text { Voltage } \\
(\%)\end{array}$} & \multirow[b]{2}{*}{$\begin{array}{l}\text { Duration } \\
\text { (s) }\end{array}$} & \multicolumn{2}{|c|}{ Standar IEEE 1159-1995 } \\
\hline & & & $\begin{array}{c}\text { Range } \\
\text { Voltage + } \\
(\%)\end{array}$ & $\begin{array}{l}\text { Duration } \\
\text { (second) }\end{array}$ \\
\hline M1 starts, M2 and M3 (off) & 32.08 & \multirow{4}{*}{0.6} & \multirow{4}{*}{10 to 90} & \multirow{4}{*}{$0.01 \mathrm{~s}$ to $1 \mathrm{~min}$} \\
\hline M2 starts, M1(on), M3 (off) & 20.43 & & & \\
\hline M3 starts, M1 and M2 (on) & 23.00 & & & \\
\hline $\mathrm{M} 1, \mathrm{M} 2$ and $\mathrm{M} 3$ start together & 62.26 & & & \\
\hline
\end{tabular}

Based on the data in Table 3, the dip voltage occurred when the motor was starting on all conditions with the magnitude ranges from $20.43 \%$ to $62.26 \%$. The greater the capacity of the motor, the dip voltage that occurred on the channel was also greater. M1 with the starting condition (32.08\%) or all three starting motors together $(62.26 \%)$ was not ideal because it could cause other problems in power system network, such as the inability of sensitive electrical load, disruption of function of equipment motor control and others. The voltage dip values that occured in all conditions are seen to exceed the standard limits based on IEEE (Institute of Electrical and Electronics Engineers) Std.1159-1995. 


\section{Conclusion}

The magnitude of a dip voltage at the motor starting in any condition was ranging from $20.43 \%$ to $62.26 \%$. This condition proved to have exceeded the permitted standard that exceeds $10 \%$. It is a condition that can cause problems in the electrical system. The proposed solution is to use an inverter as a great starting motor method considering the possibility of current and voltage harmonics due to the use of inverter.

\section{References}

[1] P.K. Lim, D.S. Dorr. Understanding and resolving voltage sag related problems for sensitive industrial customers. Power Engineering Society Winter Meeting, 23-27 January (Singapore, 2000). IEEE 4:2886-2890(2002). http://ieeexplore.ieee.org/document/847343/authors?ctx=authors

[2] G. Ranko, M. Eugen, L. Marko. Voltage dips influence zone and propagation through the industrial facility. Power Tech, 27-30 June (St. Petersburg, Russia, 2005). http://ieeexplore.ieee.org/document/4524585/

[3] R.C. Dugan, M.F. McGranaghan, S. Santoso, H.W. Beaty. Electrical power systems quality. New York: McGraw-Hill (2002). pp. 79-81. https://www.amazon.com/Electrical-Power-Systems-QualitySantoso/dp/007138622X

[4] A.C. Wang, J.H. Teng, C.C. Shen, C.N. Lu, Y.T. Chen, C.Y. Huang, E. Liu. Voltage sag vulnerability study in power system planning. Power Engineering Society General Meeting, 16 June (San Francisco, 2005). IEEE, pp. 383-388(2005). http://ieeexplore.ieee.org/abstract/document/1489434/

[5] L. Luna, L. Gallego, M. Romero. Evaluation and identification of critical zones due to sag activity. The 14th International Conference on Harmonics and Quality of Power (ICHQP), 26-29 September (Bergamo, Italy, 2010). IEEE, pp. 1-5(2010). http://ieeexplore.ieee.org/document/5625312/

[6] M. Bollen, M. Häger, C. Roxenius. Voltage dips in distribution systems: Load effects, measurements and theory. The $17^{\text {th }}$ International Conference on Electricity Distribution, 12-15 May (Barcelona, 2003). CIRED 2(47):1-5(2003).

https://www.researchgate.net/publication/229005708 Voltage dips in distribution systems Load effects measurements and theory

[7] R.C. Seebald. IEEE Power Engineering Review PER-5(9):61-62 http://ieeexplore.ieee.org/document/5526472/

[8] J.C. Das. Power system harmonics and passive filter designs. New Jersey: John Wiley \& Sons. (2015). pp. 332-334. https://www.wiley.com/en-us/Power+System+Harmonics+and+Passive+Filter+Designs-p9781118861622

[9] W.D. Stevenson. Elements of power system analysis. $4^{\text {th }}$ edition. Singapore: MC-Hill Internasional Book Company (1982). pp. 133-136. https://www.amazon.com/Elements-Analysis-ELECTRICAL-COMPUTERENGINEERING/dp/0070612781

[10] IEEE Power \& Energy Society. IEEE recommended practice for monitoring electric power quality. New York: IEEE (2009). pp. 46-51. http://ieeexplore.ieee.org/document/5154067/ 